\title{
A Qualitative Study of Attitudes towards Smoking and Anti-Smoking Measures among Korean Male Smokers in Australia
}

\author{
Yoojin Choi $^{1} \&$ Cathy Banwell ${ }^{2}$ \\ ${ }^{1}$ Rsearch School of Population Health, Australian National University, Canberra, Australian Capital Territory, \\ Australia \\ ${ }^{2}$ National Centre for Epidemiology and Population Health, Australian National University, Canberra, Australian \\ Capital Territory, Australia \\ Correspondence: Yoojin Choi, Research School of Population Health, Australian National University, Canberra, \\ Australian Capital Territory, Australia. E-mail: u5852850@anu.edu.au
}

Received: September 22, 2017 Accepted: October 25, 2017 Online Published: October 31, 2017

doi:10.5539/gjhs.v9n12p131 URL: https://doi.org/10.5539/gjhs.v9n12p131

\begin{abstract}
The study aims to explore how Korean male smokers living in Australia talk and feel about smoking and how they have understood and experienced tobacco control policies in Australia-including price increase, display ban, plain packaging, and graphic warning labels. A qualitative study was conducted based on in-depth face-to-face interviews with 8 Korean male smokers aged 23-40 years living in Canberra. Participants discussed social and cultural conditions in Korea under which smoking is practiced and maintained. Smoking as a means of socialising and relaxation were consistently discussed as the main reasons for continued smoking which was deeply embedded in their everyday lives as habit or part of routines. The health risks of smoking were not among the immediate or ultimate considerations influencing participants. Participants commented that price increases had affected them most but other measures had little impact on their smoking behaviours, although they acknowledged their potentials in deterring younger people. Future anti-smoking interventions in Korea should address the significant social and cultural determinants of smoking and acknowledge smokers' own understanding of their smoking and anti-smoking measures. Appreciating smokers' diverse representations of their own smoking and their attitudes towards health and anti-smoking measures would increase acceptance of policies and the probability that they will be successful, leading to positive outcomes.
\end{abstract}

Keywords: anti-smoking measure, Australia, continued smoking, health risk, Korean male smoker, qualitative study

\section{Introduction}

Tobacco smoking is one of the world's biggest public health threats, killing roughly 6 million people worldwide yearly (World Health Organisation [WHO], 2016). Smoking has a myriad of negative impacts on health, including sudden infant death syndrome, cardiovascular diseases, cancers (especially lung cancer), and respiratory diseases (WHO, 2012). Tobacco is expected to kill nearly one billion people during the 21 st century if urgent action is not taken (WHO, 2011).

Smoking is a major cause of death and disease in South Korea (hereafter "Korea") (Cho, Khang, Jun, \& Kawachi, 2008). Smoking is to have been implicated in the deaths of an estimated 47,684 Koreans, and it is estimated that roughly $21 \%$ of deaths was attributable to smoking in 2004 (WHO, 2012). The estimated total health costs related to smoking increased from US\$324.9 million in 1999 to US\$413.7 million in 2003 (Chung, Kim, Lim, Lee, \& Cho, 2009). Additionally, the socioeconomic costs of smoking have risen by $60 \%$ from 4.4 trillion won (approximately US\$3.9 billion) in 2005 to 7.1 trillion won (US\$6.3 billion) in 2013 (Lee, Yoon, Baek, Hyun, \& Kang, 2015). These findings demonstrate that smoking needs to be an important public health target in Korea.

A range of anti-smoking measures have been implemented in Korea relatively recently (French, Jang, Tait, \& Anstey, 2013), although limited progress in reducing smoking has been made compared to Australia. At the time this study was conducted (February to June 2017), Korea and Australia differ remarkably, both in smoking rates and anti-smoking measures enforced. While Australia has achieved one of the lowest smoking rates among men aged over 15 years in the world (14.7\% in 2013), Korea has the second highest level among members of 
Organisation for Economic Cooperation and Development [OECD] (36.6\% in 2014) (OECD, 2017). Australia is internationally renowned for its stringent anti-smoking measures especially since it became the first country to fully implement plain packaging of tobacco products in December 2012 (Yong et al., 2016). Also, Australia is the only country in which tobacco excise increases in line with wage inflation to ensure that tobacco products do not become relatively more affordable over time, with the effect of producing cigarettes that are among the most expensive in the world (WHO, 2015). Furthermore, the Australian government announced an additional 12.5\% tobacco excise increase from 2017 to 2020 yearly (Department of Health, 2017). These measures apparently contrast to Korea where cigarette prices are still remarkably lower than OECD average despite an $80 \%$ price increase in 2015 (Kim, 2016), which was the first increase since 2004. Moreover, while a partial tobacco advertising restriction operates in Korea, a comprehensive ban on tobacco advertising had been enforced in Australia. Also, a display ban of tobacco products had been implemented in Australia with limited exemptions (Dunlop et al., 2015; The Cancer Council, 2017). In contrast, tobacco displays and advertising in retail environments are still allowed in Korea (Cho, 2014). While the Korean government implemented graphic warning labels in December 2016, requiring health warnings to cover at least $50 \%$ of both sides of packs, expanded health warnings with graphic warning images cover $75 \%$ of the front and $90 \%$ of the back of packs in Australia (Canadian Cancer Society, 2016).

In the context of tobacco control interventions, smoking has frequently been framed as a risky behaviour resulting from individual lifestyle choices, uninfluenced by social and cultural contexts (Poland et al., 2006; Heikkinen, Patja, \& Jallinoja, 2010; Bell, Salmon, \& McNaughton, 2011). Smokers are assumed to voluntarily exercise control over their behaviour for the ultimate benefit of their health in predetermined ways designed by anti-smoking interventions without being influenced by their individual, social, and cultural circumstances (Gilbert, 2008; Dennis, 2013). These anti-smoking measures are justified by epidemiological knowledge about the health risks of smoking (Heikkinen et al., 2010). The problem looks simple; smoking is bad for your health, therefore stop smoking (Laurier, McKie, \& Goodwin, 2000). However, as many previous studies (Petersen \& Lupton, 1996; Frohlich, Corin, \& Potvin, 2001; Dennis, 2013) have indicated, such individualistic understandings of smoking tend to ignore social, cultural, economic, and political circumstances as if there were no sociocultural contexts, systematic influences, or social meanings given to the behaviour. Although smoking behaviour involves an element of personal choice, it arises from combination of individual factors and sociocultural contexts (Jarvis \& Wardle, 2006). As Williams (1995) claimed, how social and cultural structures in which people live have influenced their behaviour and the meanings placed upon smoking behavior itself should be considered when talking about smokers' choice to smoke, especially in an unfriendly environment towards smoking.

Few qualitative studies have explicitly explored the meanings that Korean male smokers ascribe to smoking, the sociocultural contexts in which they smoke, or their experiences of anti-smoking interventions. Only a few studies have been conducted among adolescents (Kim, Cho, \& Lee, 2001) and female undergraduate students (M. S. Kim \& A. K. Kim, 1997; Jeong et al., 2010). This lack of studies has led us to explore the accounts of Korean male smokers exposed to smoking restrictions in Australia. The aims of this study were to explore how Korean male smokers living in Australia talk and feel about smoking and how they have understood and experienced tobacco control policies in Australia - including price increase, display ban, plain packaging, and graphic warning labels. The Korean government has a goal of reducing the smoking prevalence among adult men to $29 \%$ by 2020 (Korea Health Promotion Foundation, 2015). It would be expected that exploring the Korean male smokers' representation of smoking and their experiences of strong anti-smoking measures in Australia represents directions that anti-smoking interventions in Korea could move towards. We also wished to explore how social and cultural factors have influenced Korean male smokers' behaviours and how they talk about anti-smoking messages related to health. Increasing the knowledge of broad structural factors surrounding smoking and smokers' understanding of the health risks may be useful for developing more successful and targeted interventions.

\section{Method}

\subsection{Participants}

A purposive sample of 8 Korean male smokers aged between 23-40 years were recruited from Canberra. This number of participants was recruited based on research suggesting that the amount of new information or insights gained from additional interviews diminishes from this point onwards in a homogenous group (Guest, Bunce, \& Johnson, 2006). They were recruited by various methods including personal contacts, a snowball sampling, and through a post on the Facebook page of the Korean Postgraduate Society at Australian National University. The eligibility criteria for participants were that they had to (a) be a smoker in Korea, (b) have been living in Australia for at least 6 months to ensure exposure to anti-smoking measures, and (c) be currently smoking. Participants were 
contacted by the first author who provided them with information about the study and set up a time and place for an interview. Table 1 presents participants' demographic information and various factors about their current smoking status. All participants have been given pseudonyms to ensure their privacy.

Table 1. Demographic information and current smoking status

\begin{tabular}{|c|c|c|c|c|c|c|c|c|}
\hline Name & Age & $\begin{array}{l}\text { Education } \\
\text { Level }\end{array}$ & Occupation & $\begin{array}{l}\text { Length of } \\
\text { residence in } \\
\text { Australia }\end{array}$ & $\begin{array}{l}\text { Age smoked } \\
\text { first cigarette }\end{array}$ & $\begin{array}{l}\text { Number of } \\
\text { years as a } \\
\text { smoker }\end{array}$ & $\begin{array}{l}\text { Number of } \\
\text { cigarettes } \\
\text { smoked per day }\end{array}$ & $\begin{array}{l}\text { Intention to } \\
\text { quit in } 6 \\
\text { months }\end{array}$ \\
\hline Jaehoon & 40 & Postgraduate & $\begin{array}{l}\text { Part-time PhD student } \\
\text { / Health professional }\end{array}$ & 7 months & 21 & 20 & $2-3$ & No \\
\hline Dohwan & 23 & $\begin{array}{l}\text { University } \\
\text { dropout }\end{array}$ & $\begin{array}{l}\text { Language school } \\
\text { student / Part-time } \\
\text { cook }\end{array}$ & 14 months & 14 & 10 & $15-20$ & No \\
\hline Seongwoo & 28 & High school & Part-time cook & 10 months & 19 & 10 & $15-20$ & No \\
\hline Saejoon & 23 & $\begin{array}{l}\text { 3rd year in } \\
\text { University }\end{array}$ & $\begin{array}{l}\text { Full-time University } \\
\text { student / Part-time } \\
\text { waiter }\end{array}$ & $>6$ years & 14 & 10 & $2-3$ & No \\
\hline Suhyun & 26 & Bachelor & $\begin{array}{l}\text { Technical Institution } \\
\text { student / Part-time } \\
\text { cook }\end{array}$ & $>3$ years & 13 & 10 & $5-6$ & No \\
\hline Beomseok & 26 & $\begin{array}{l}\text { Advanced } \\
\text { diploma }\end{array}$ & Full-time cook & 5 years & 14 & $10-12$ & $10-15$ & No \\
\hline Hojin & 24 & $\begin{array}{l}\text { 3rd year in } \\
\text { University }\end{array}$ & $\begin{array}{l}\text { Full-time University } \\
\text { student }\end{array}$ & 4 years & 14 & 11 & 1 & No \\
\hline Jiyoung & 26 & Bachelor & $\begin{array}{l}\text { Technical Institution } \\
\text { student }\end{array}$ & 2 years & 17 & 5 & $2-3$ & No \\
\hline
\end{tabular}

\subsection{Data Collection}

The study was approved by the Australian National University's Human Ethics Research Committee. In-depth face-to-face interviews were conducted between March and April 2017 to obtain deep and reliable understandings of participants' own experiences and perceptions of smoking and Australia's anti-smoking interventions in their everyday lives "as expressed in their own words" (Taylor \& Bogdan, 1984, pp. 77).

The interviews, lasting between 37-59 minutes, took place in a comfortable location for participants, and followed a semi-structured format based on an interview topic guide developed on the basis of a review of the relevant literature. It covered a range of topics, including (a) smoking history, (b) current smoking behaviours, (c) reasons for smoking, and (d) understandings and experiences of Australia's anti-smoking measures.

An information sheet and consent form were provided to all participants prior to the interviews. All interviews were audio-taped with the consent of the participants, and transcribed verbatim by the researcher. During interviews and throughout data analysis, the researcher paid particular attention to critically reflecting on her own role to reduce social desirability effects. Once the interview was finished, the researcher debriefed the participant and provided information about smoking cessation resources. Participants received a $\$ 10$ gift card to recognise their time and efforts. All interviews were conducted by the first author in Korean. Interview data were transcribed and analysed in Korean and final findings were translated into English as accurately as possible, and kept in context to preserve the subtle nuances of Korean.

\subsection{Data Analysis}

The transcripts were analysed using thematic analysis, the most commonly used analysis method in qualitative research (Guest, MacQueen, \& Namey, 2012). It is useful and flexible in identifying, analysing, and reporting patterns or themes, providing "a rich and detailed, yet complex account of data" (Braun \& Clarke, 2006, pp. 78). Atlas.ti, a qualitative data management software, was used to manage data coding to facilitate the analysis transcripts (Mays \& Pope, 1995). Following Braun and Clarke (2006), the first author read and re-read all 
transcripts closely several times to become familiar with the data before engaging in intensive analysis. Secondly, initial codes were generated, considering both manifest and latent contents within the data (Vaismoradi, Turunen, \& Bondas, 2013), and a codebook was developed. A precise and descriptive codebook ensured coherence among codes and reliability of coding (Guest et al., 2012). Thirdly, after all data had been initially coded, different codes were sorted into a broader level of potential themes using a thematic map. Codes were constantly compared with the data, other codes, and memos on codes or themes, which helped to validate the account of the data (Richards, 2005). Fourthly, themes running across the data were refined to make sure that codes and themes reflect the whole data and capture something important related to the research questions (Vaismoradi et al., 2013). Codes and themes were discussed with the second author and reviewed repeatedly as the data analysis process progressed. Fifthly, the themes were further defined and named. The analysis of data was guided by pre-existing themes from the literature, interview topic guide, and emerging themes from the data.

\section{Results}

\subsection{A Smoky Environment in Korea}

Participants discussed social and cultural conditions in Korea under which smoking is practiced and maintained, which they called "the several environmental factors" or "social culture". They mainly proposed that mandatory military service, cultural pressure to conform or military culture, and a stressful and harsh life have contributed to high smoking prevalence.

Some participants said that they started to smoke again, became regular smokers, or smoked heavily during their military service. Smoking was used to pacify their mind and body after long and tiring military trainings, to take breaks, or to deal with boredom:

"I smoked more in military... I naturally craved cigarettes as training was hard." (Dohwan)

"If you don't smoke, you don't have a break." (Suhyun)

Some participants mentioned that there is strong pressure to conform in Korean society, which partly contributed to high smoking rates:

"We should follow them when people in the higher position in the military or in the workplace suggest going out to smoke." (Saejoon)

Suhyun described how military culture, the idea of valuing strong hierarchy and obeying a strict chain of command, facilitated smoking:

"People who hadn't smoked before smoke during their military service.... Many people had got to smoke due to kind of pressure."

Participants attribute the high smoking rates to the stressfulness and struggle of living in Korean society. Seongwoo said: "As people haven't got time to relax, many people would smoke to find a little relaxation during the day."

He argued that smoking gives ordinary people short breaks in a fast-faced and competitive life. Beomseok similarly thought that smoking is a meaningful and affordable way to relieve stress and cope with pressure. He noted that people rely on smoking as there is much pressure but limited other opportunities to enjoy leisure activities in Korea: "The easiest and fastest way to find pleasure is smoking."

It appears that broad socio-cultural pressure and a compulsory, hierarchical, and military culture serve to facilitate and maintain smoking practices in Korean male society.

\subsection{Being a Korean Male Smoker}

\subsubsection{Smoking as a Means of Socialising}

In Korea, as elsewhere, smoking initiation and maintenance was associated with participants' social lives (Collins, Maguire, \& O'dell, 2002; Fry, Grogan, Gough, \& Conner, 2008). Participants described smoking in groups; sharing a cigarette break with work colleagues, smoking in social gatherings especially when drinking, after meals and so on:

"When traveling, we smoke together right after waking up and having meals. Literally we smoke just because we're together whatever we're doing." (Dohwan)

Many participants said smoking made them feel that they belonged to a group with the amount they smoked influenced by people around them. Smoking serves as a social ritual (Mausner \& Platt, 1971), with participants smoking to facilitate a social or group identity (Collins et al., 2002). 
They thought it enhanced solidarity, strengthened bonds, and maintained social relationships:

"I can't help but getting along well with those people because we've got time to talk about work and other things more deeply smoking together." (Seongwoo)

Participants claimed that one of the reasons they could not stop smoking was because their friends smoked:

"When my friends are smoking I feel like I need to follow them and smoke. So I smoke more and more." (Dohwan)

\subsubsection{Smoking as Relaxation and Habit}

Smoking, though it was part of participants' social lives, was also a solitary source of relaxation. It was typically used to manage stress, to control emotional states, or to take a break from work or study. Above all, the link between stress and smoking was emphasised: "When I'm stressed out at work, I'm like, 'Let's go out for a smoke."' (Suhyun) Smoking was described as a natural or reasonable response to stressful and difficult situations in participants' lives. They described smoking as relieving and pacifying. The benefit of smoking in terms of alleviating stress was intertwined with the difficulty of quitting. Jiyoung observed:

"I can't avoid feeling stressed. It's right to quit, but I've got to think of smoking as these situations keep happening."

Smoking was also described as an emotional reward at the end of the long day:

"After school I go to work, and after work I need to study, which is tough. And I feel lonely.... It's like a compensation, feeling, 'I've got through the day well.'” (Dohwan)

His account clearly indicates that smoking was constructed as a coping strategy to help him get through his life and control his emotions. Smoking was used as a reward, which was a ritual to celebrate the end of the day.

Smoking to relieve stress and manage certain circumstances and emotions has to do with the construction of smoking as habit or ritual (Collins et al., 2002): "It's a sort of ritual, because it's become conditioned to smoke when I feel stressed." (Jaehoon)

Smoking has been developed as habit or ritual in most participants' lives as they have been smoking for a long time. Participants described having psychological addiction to the habit of smoking, which is cued by certain circumstances and emotional states or behaviours that are a source of stimuli for smoking. Seongwoo experienced his smoking as an integral part of daily routines and situations: "I smoke every two hours, after meals, or when I'm stressed out at work?"

This habitual or routinized smoking was practiced "naturally or without conscious thoughts":

"I want to smoke unconsciously because it's become one of habits not like a conscious craving for smoke." (Hojin)

The construction of smoking as a habit explained why participants found it difficult to stop smoking: "As it's the same for all habits, it's hard to break." (Dohwan)

\subsubsection{Dealing with the Health Risks of Smoking}

All participants stated their awareness of the health risks of smoking, but none of them had a specific plan to quit in the near future. Rather, they sought to defend and explain their continued engagement in "risky behaviour" by demonstrating the ways of dealing with the health risks, in ways that are not usually acknowledged by public health professionals. For example, Beomseok said,

"I try to ignore health risks as much as possible.... It's better to smoke without thinking about them rather than considering them and feeling stressed."

Seongwoo showed fatigue with public health messages that he already knew: "I'm already immune to them and I'm well-aware of them." His account indicates that smokers do not find anti-smoking messages informative rather they feel "fed up". Moreover, some participants questioned the negative health consequences of smoking. They subjectively constructed health risks through their personal experiences and continued to smoke. For instance:

"I had cancers and lung-related diseases checked. The result came out so good and my lung capacity was better than others." (Beomseok)

It would appear that constructing themselves as being aware of the health consequences but not being affected by them yet positions smokers as not having to stop smoking in a sensible way (Scheffels \& Schou, 2007).

Also participants regarded smoking-related risks as unpredictable future events: "It's unrealistic, but what I need right now is in front of me." (Seongwoo)

It seems that health concerns are subordinate because Seongwoo's present desire for smoking and immediate 
benefits of smoking are more important and stronger. As Collins et al. (2002) suggested, smokers may not think of the health effects of their smoking in normal day. Most participants thought that people do not necessarily behave as a "healthy citizen" whose duty is "to achieve and preserve good health, so that one might fulfil the other obligations of citizenship" (Petersen \& Lupton, 1996, pp. 65):

"We don't sacrifice ourselves to improve health and increase life expectancy of the country by leading a strict life." (Jaehoon)

Jaehoon mentioned that although people acknowledge health issues related to their behaviour, they do not necessarily reflect on their behavior and behave "rationally" (Gilbert, 2005), thus demonstrating that it is misleading to assume that health is the "golden standard" for everyone (Gilbert, 2005, pp. 229) as public health policies assume under the prevalent discourse of "healthism" where the pursuit of good health has become an end itself (Lupton, 1995).

\subsection{Being a Korean Male Smoker in Australia}

\subsubsection{Experiences of Expensive Cigarettes}

Korean male participants brought entrenched smoking practices with them to Australia. They noted that cigarettes were far more expensive in Australia, making price the most marked difference between Australia and Korea. Most reported that high cigarette prices had led them to reduce the amount they smoke or motivated them to quit: "I smoke less. I have to spend nearly half of my daily wage to buy a pack." (Dohwan)

"It keeps me thinking that I should quit. I'd end up quitting one day." (Beomseok)

Other studies (Ross, Blecher, Yan, \& Hyland, 2011) have found higher cigarette prices contributed to the greater motivation to stop smoking and likelihood of quitting among adult smokers in the US and Canada. Our participants highlighted that cheap cigarettes contribute strongly to the high smoking prevalence in Korea and a substantial price increase would be likely to reduce smoking rates, particularly among younger people:

"Smoking rates among adolescent would be significantly reduced ... It can't be a thing like 'Oh, I'm bored. Let's get a cigarette." (Jaehoon)

\subsubsection{Experiences of Display Ban}

Many participants compared Australia to Korea where people are exposed to the sight of cigarettes packs in retail environments. Some said that it gave an impression that smoking is encouraged whereas in Australia cigarettes were subject to sanctions:

"It's totally covered here. I felt smoking is more regulated like a target of sanctions." (Jiyoung)

However, all participants commented that display ban did not lead them to quit or reduce their cigarettes consumption: "I don't think it makes me not to smoke. It's just irritating." (Suhyun)

However, some participants supported reducing the visibility of cigarette packs and they acknowledged its potentials in deterring young people:

"It's good for young people ... People unconsciously eat fast-food as they're exposed to them a lot. It's the same for cigarettes. People exposed more often are more likely to smoke." (Beomseok)

This view corresponds to a previous study (Dunlop et al., 2015) which suggests that the display bans on cigarettes in retail environments could contribute to the denormalisation of smoking among young people.

\subsubsection{Experiences of Plain Pack}

Participants described plain packs as "less appealing" and "kind of like a drug in dark colour" and acknowledged that plain packaging might diminish the appeal of smoking, particularly for young people and others who think smoking looks cool:

"I can't say packaging reduces smoking rates among smokers, but basically, it doesn't have impulsive impacts on potential smokers." (Hojin)

While plain packs were perceived negatively by some participants and many of them acknowledged its potential to deter younger people, most participants argued that plain packs had not made any changes in their own smoking behaviours. Beomseok who has experienced the packaging change said that the packaging change has not affected him at all. For established smokers the shape or the packaging does not seem to be a "big deal": "Smokers don't care much about the pack because they're people smoking anyways." (Hojin)

Many participants commented that smokers have more interest in smoking itself than the appearance of cigarette 
packs, and thought that current smokers would continue to smoke regardless of it. Interestingly, Saejoon commented how smokers could act in the ways that would challenge the core assumption of plain packaging that smokers are to face warning labels "each and every time they reach for a cigarette" (Bell, Dennis, Robinson, \& Moore, 2015, pp. 139): "They might look more apparent, but it's useless because we can just not look at them and read them."

\subsubsection{Experiences of Graphic Warning Labels}

While some participants described graphic warning labels as "disgusting", "dirty", or "terrible", others reported that they felt indifferent and had not paid much attention to them in the first place:

"There're several regulations like packaging, warning phrases, and warning images. They've never caught my eyes." (Beomseok)

Some participants thought that pictorial warning labels would work on young people but not themselves: "I haven't been affected by the pictures. I tend to regard them as part of packs." (Jiyoung)

They were skeptical about graphic warning labels mainly because of smokers' strong desire, addiction, or force of habit: "The body itself craves it like a real habit." (Dohwan)

They tended to diminish the relevance of health risks to themselves and continued to smoke. Previous studies (Gough et al., 2009; Heikkinen et al., 2010; Hardcastle et al., 2016) have also found that smokers did not recognise their own personal vulnerability to smoking-related diseases.

Furthermore, some participants doubted the legitimacy of warning images. Hojin said, "The photos are composite ones with some contrast and highlight made by Photoshop to arouse attention."

He believed that images were fabricated to get desired outcomes, and it led him to question the credibility of messages, which corresponds to the existing research (McCool, Webb, Cameron, \& Hoek, 2012; Hardcastle et al., 2016).

Participants reported that the messages that warning images try to convey were not persuasive because they already knew them: "I can't understand the point. We're smoking anyways knowing that smoking is bad." (Saejoon)

It seems difficult to illicit behaviour changes among established smokers who acknowledged the consequences of their smoking and raises questions about the underlying assumption that graphic warning labels could affect behavioural change by educating individuals about the health effects of smoking (Haines-Saah, Bell, \& Dennis, 2015).

Dohwan suggested that the government could have used positive messages such as successful cessation stories or advice rather than negative and disgusting pictures which reproduce information that they already know. The finding corresponds to Bandura (1997, pp. 280-281) who suggested, "public health messages that elicit positive emotions make people feel more efficacious and optimistic about the benefits of new healthful practices than do messages that arouse fear". Jaehoon summarised the general views towards graphic warning labels discussed across participants: "This behavioural approach mixing negative stimulus is old-fashioned."

\section{Discussion}

This paper aimed to provide rich insights into how Korean male smokers reflect upon their smoking and their experiences of anti-smoking measures in Australia. It identified sociocultural structures in Korea under which smoking is practiced and maintained and why participants continue to smoke despite acknowledging the health risks. It provided deep understandings of how Korean male smokers have experienced anti-smoking interventions in Australia.

Smoking is a complex phenomenon, involving several factors, which cannot be simply reduced to an individual risky behaviour (Gilbert, 2005). Korea is filled with social and cultural symbols legitimising smoking if not actually encouraging it. Compulsory two years of military service for Korean males partly facilitated smoking by giving either free and duty-free cigarettes, or an allowance until 2009 (Kim, Son, \& Nam, 2005; Allem, Ayers, Irvin, Hofstetter, \& Hovell, 2012). Society-wide and military pressure to conform to social norms is reinforced by Confucian culture where harmony and hierarchy are valued (Schwekendiek, 2016), and it is the relationships of the person to others that determine people's behaviour rather than their personal wishes or attributes (Markus \& Kitayama, 1991). Smoking is deeply ingrained in Korean male society, which sharply contrasts to negative sociocultural norms towards women's smoking leading to the lowest smoking rates of female aged over 15 years among OECD countries (Cho et al., 2008; OECD, 2017). Also, in a highly stressful Korean society where there are 
little other available coping resources, smoking has been positioned as an antidote or coping mechanism (Collins, 2004). Other studies (Poland et al., 2006; Scheffels \& Schou, 2007; Gilbert, 2008; Haines-Saah et al., 2015) highlighting the importance of social and cultural contexts support the contention that smoking is sustained by social and cultural structures in Korea.

Cigarette use involves various symbols and mutually understandable cues among participants (Nichter, 2003). Smoking facilitated socialisation, relieved stress, controlled certain situations and emotions, and provided a break for participants, making it difficult to quit. As Lupton (1995) suggested, what seems important to smokers is what smoking represents, a space and time to build social bonds, to calm themselves, to collect thoughts, and to rest. This is important in that it reflects and reinforces smoking through establishments of the appropriateness of smoking in certain groups of people and circumstances (Katainen, 2010). Participants experienced smoking as being deeply ingrained in their everyday lives as habit or part of routines, practiced "naturally or without conscious thoughts". Sociocultural structures in Korea, which have been incorporated into individuals' smoking practiceswhat they think and do-serve to facilitate and maintain smoking behaviour (Poland et al., 2006). Smoking acquires its meanings as a result of the complex interaction of wider sociocultural structures and the agency of smokers, who practice it (Frohlich et al., 2001; Poland et al., 2006). This makes it difficult to regard smoking as a simple deviant and irrational behaviour that could be easily separated from its surroundings (Mair, 2011).

Growing up and going through the teenage years in Korea where smoking is strongly embedded have perhaps contributed to participants' resistance towards anti-smoking messages in Australia. Participants' attitudes towards the health risks of smoking explained their continued smoking in an environment where smoking is strongly regulated and information about health risks is widespread. While participants acknowledged the health consequences of smoking, they managed to deal with them in ways that differ from the ways predicted by those who develop anti-smoking messages (Katainen, 2006). The finding corresponds with a previous study (McMaster \& Lee, 1991) which has shown that smokers experience cognitive dissonance where they acknowledge the health risks but justify their smoking to continue it. It questions the widespread public health assumption which positions smokers as "rational agents who need only to be presented with the facts to respond appropriately" (Macnaughton, Carro-Ripalda, \& Russell, 2012, pp. 458). Healthy practices do not stand alone from other practices in participants' everyday lives, and they can be subordinated to the desire to smoke or the benefits of smoking that participants regarded as more important (Lupton, 1995). As Crawford (2004, pp. 509) suggests, "health is not the only light in the sky"; there are a range of values that participants put an emphasis on, which is not always consistent with public health discourse that takes "health" as the ultimate value, and limits their willingness to comply with anti-smoking measures.

Korean male smokers perceived that Australia's anti-smoking interventions other than price increase had little to do with changing their smoking behaviours, although they acknowledged their potential impacts on younger people. They shared a general view that the price increase had encouraged them to reduce their smoking or encouraged them to quit. They indicated that high affordability of cigarettes is the critical factor for high smoking rates in Korea, and suggested that a substantial price increase would be the only way to effectively reduce smoking rates. It corresponds to the report by International Tobacco Control Policy Evaluation Project (2012) which has identified cheap cigarettes and low rate of increases as the major contributors to the continued high smoking prevalence in Korea. Increasing cigarettes price is believed to be effective in reducing cigarette consumptions and smoking prevalence (WHO, 2015) by encouraging smokers to quit, deterring potential smokers from starting to smoke, and reducing relapse (Gardner \& West, 2010).

Graphic warning labels on plain packs did not lead to changes in participants' smoking behaviours. Others (Hastings \& MacFadyen, 2002) suggest that graphic warning labels do not encourage changes in existing smoking behaviour. The crucial role of cigarette pack design in tobacco companies' marketing strategies has been well documented (Freeman, Chapman, \& Rimmer, 2008), and empirical studies (Wakefield et al., 2015) have demonstrated that graphic warnings on plain packs have encouraged people to quit. Nevertheless, as Haines-Saah et al. (2015) suggested, graphic warning labels which fail to address the reasons why people may smoke other than addiction, and frame smoking as an individual risky behaviour entirely isolated from its social contexts, are likely to be ineffective, given that the difficulty of quitting is intertwined with social and emotional benefits of smoking. The findings of the study suggest that there should be a careful consideration that smoking is a complex phenomenon involving interactions of several factors, that it has socially and culturally constructed meanings and is habitual, and that good health is not the ultimate consideration in people's everyday lives. Instead of fear arousing messages, supportive messages showing greater respect for individuals could increase the belief that quitting is worthwhile and achievable (Wolburg, 2006). 
The study was not intended to assess the effectiveness of anti-smoking measures designed to reduce smoking prevalence in Australia. Rather, it aimed to obtain insights into how Korean male smokers from a country where smoking still remains prevalent and with less strong tobacco control interventions compared to Australia have experienced and been impacted by them. It was expected that it might provide valuable perspectives or implications for developing effective anti-smoking interventions in Korea. Based on this study it seems that substantial price increase in cigarettes would be the most effective measure. It appears that regulations on cigarette packs display and packaging are less likely to deter current smokers, but could be important areas for policy change targeting potential smokers. Smoking in the military should be tackled as it exposes almost all young Korean males to a pro-smoking environment and culture, which could influence them for a lifetime. Targeted approaches could include smoking bans on military bases, quit smoking support groups, and promoting a supportive environment for quitting.

The findings should be considered in light of several limitations. As the study was based on a small purposive sample, it would not be representative of Korean male smokers in Australia. While it was intended that the findings would have implications for anti-smoking policies in Korea, this was limited by several factors. The experiences and attitudes of Korean male smokers in Australia towards anti-smoking interventions might be different from those in Korea. However, given that there were no clear differences emerging among participants depending on their length of residence in Australia, their understandings are not expected to be largely different from those of most Korean male smokers in Korea. Also, considering the difference in attitudes and understandings of smoking and anti-smoking measures among different age groups and socioeconomic classes (Fry et al., 2008), the study mostly focusing on young Korean male smokers with relatively high education would be limited in presenting the views of other age groups and socioeconomic classes in Korea. However, the study exploring the meanings that Korean male smokers ascribe to smoking and their accounts of anti-smoking measures has much to contribute to the greater understanding of how smokers perceive their smoking practices and how the government policies to regulate their behaviour are perceived and understood in their everyday lives.

Given that the study was conducted in a specific context in Australia, with a small number of participants, further research could explore how Korean smokers think about smoking and anti-smoking interventions in the Korean context. Many participants suggested that display ban and plain packaging would work on young people. Given that there is little restriction on cigarettes packs display and packaging in Korea, future research could explore the effects of these on young people's smoking behaviours. Lastly, considering the possibility that participants' accounts may have reflected more general national or cultural narratives around smoking, health, and anti-smoking interventions, it may be worth further exploration of differences in attitudes and views among smokers in Australia and Korea.

\section{Conclusion}

Drawing upon these findings, future anti-smoking interventions in Korea should address the significant social and cultural determinants of smoking and acknowledge smokers' own understanding of their smoking and anti-smoking measures. Narrowly framing smoking as an individual's lifestyle choice and blindly trying to reduce smoking rates by using "an old-fashioned method" to persuade individuals to change their behaviour with information on the health risks is unlikely to address the social and cultural determinants and resonate with those who continue to smoke while knowing that smoking is harmful. If anti-smoking interventions are to achieve success, "they must address the socio-cultural realities that impose constraints on the exercise of personal control" (Bandura, 1997, pp. 307). Appreciating smokers' diverse representations of their own smoking and their attitudes towards health and anti-smoking measures would increase acceptance of policies and the probability that they will lead to positive outcomes (Crawford, Balch, Mermelstein, \& Tobacco Control Network Writing Group, 2002). Ultimately, as suggested by Heikkinen et al. (2010), policy makers need to use broad and positive approaches to addressing smokers' suggestions or questions such as the following: "The price is really $100 \%$. Smoking rates would be halved.", "Why should they have done it negatively when there're positive stuff to make it better?", and "It's right to reduce smoking prevalence, but it's a matter of issue requiring lots of thoughts regarding to what extent and by which means to achieve it."

\section{Acknowledgments}

We would like to thank the participants for sharing their thoughts and experiences.

\section{Competing Interests Statement}

The authors declare that there are no competing or potential conflicts of interest. 


\section{References}

Allem, J., Ayers, J. W., Irvin, V. L., Hofstetter, C. R., \& Hovell, M. F. (2012). South Korean military service promotes smoking: A quasi-experimental design. Yonsei Medical Journal, 53(2), 433-438. https://doi.org/10.3349/ymj.2012.53.2.433

Bandura, A. (1997). Self-efficacy: The exercise of control. New York, NY: W.H. Freeman and Company.

Bell, K., Dennis, S., Robinson, J., \& Moore, R. (2015). Does the hand that controls the cigarette packet rule the smoker? findings from ethnographic interviews with smokers in Canada, Australia, the United Kingdom and the USA. Social Science \& Medicine, 142, 136-144. https://doi.org/10.1016/j.socscimed.2015.08.021

Bell, K., Salmon, A., \& McNaughton, D. (2011). Alcohol, tobacco, obesity and the new public health. Critical Public Health, 21(1), 1-8. https://doi.org/10.1080/09581596.2010.530642

Braun, V., \& Clarke, V. (2006). Using thematic analysis in psychology. Qualitative Research in Psychology, 3(2), 77-101. https://doi.org/10.1191/1478088706qp063oa

Canadian Cancer Society. (2016). Cigarette package health warnings: International status report. Retrieved May 8, 2017, from http://www.tobaccolabels.ca/wp/wp-content/uploads/2016/11/Cigarette-Package-HealthWarnings-International-Status-Report-English-CCS-Oct-2016.pdf

Cho, H. J. (2014). The status and future challenges of tobacco control policy in Korea. Journal of Preventive Medicine and Public Health = Yebang Uihakhoe Chi, 47(3), 129-135. https://doi.org/10.3961/jpmph.2014.47.3.129

Cho, H. J., Khang, Y. H., Jun, H. J., \& Kawachi, I. (2008). Marital status and smoking in Korea: The influence of gender and age. Social Science \& Medicine, 66(3), 609-619. https://doi.org/10.1016/j.socscimed.2007.10.005

Chung, W. J., Kim, H. J., Lim, S. J., Lee, S. M., \& Cho, K. S. (2009). Factors influencing cigarette smoking and quantified implications for anti-smoking policy: Evidence from South Korea. International Journal of Public Health, 54(6), 409-419. https://doi.org/10.1007/s00038-009-0087-x

Collins, P., Maguire, M., \& O'dell, L. (2002). Smokers' representations of their own smoking: A Q-methodological study. Journal of Health Psychology, 7(6), 641-652. https://doi.org/10.1177/1359105302007006868

Collins, R. (2004). Interaction ritual chains. Princeton, NJ: Princeton University Press. https://doi.org/10.1515/9781400851744

Crawford, M. A., Balch, G. I., Mermelstein, R., \& Tobacco Control Network Writing Group. (2002). Responses to tobacco control policies among youth. Tobacco Control, 11(1), 14-19. https://doi.org/10.1136/tc.11.1.14

Crawford, R. (2004). Risk ritual and the management of control and anxiety in medical culture. Health, 8(4), 505-528. https://doi.org/10.1177/1363459304045701

Dennis, S. (2013). Researching smoking in the new smokefree: Good anthropological reasons for unsettling the public health grip. Health Sociology Review, 22(3), 282-290. https://doi.org/10.5172/hesr.2013.22.3.282

Department of Health. (2017). Tobacco. Retrieved February 16, 2017, from http://www.health.gov.au/internet/main/publishing.nsf/content/tobacco-tax

Dunlop, S., Kite, J., Grunseit, A. C., Rissel, C., Perez, D. A., Dessaix, A., ... Currow, D. (2015). Out of sight and out of mind? Evaluating the impact of point-of-sale tobacco display bans on smoking-related beliefs and behaviors in a sample of Australian adolescents and young adults. Nicotine \& Tobacco Research, 17(7), 761-768. https://doi.org/10.1093/ntr/ntu180

Freeman, B., Chapman, S., \& Rimmer, M. (2008). The case for the plain packaging of tobacco products. Addiction, 103(4), 580-590. https://doi.org/10.1111/j.1360-0443.2008.02145.x

French, D. J., Jang, S., Tait, R. J., \& Anstey, K. J. (2013). Cross-national gender differences in the socioeconomic factors associated with smoking in Australia, the United States of America and South Korea. International Journal of Public Health, 58(3), 345-353. https://doi.org/10.1007/s00038-012-0430-5

Frohlich, K. L., Corin, E., \& Potvin, L. (2001). A theoretical proposal for the relationship between context and disease. Sociology of Health \& Illness, 23(6), 776-797. https://doi.org/10.1111/1467-9566.00275

Fry, G., Grogan, S., Gough, B., \& Conner, M. (2008). Smoking in the lived world: How young people make sense of the social role cigarettes play in their lives. British Journal of Social Psychology, 47(4), 763-780. https://doi.org/10.1348/014466608X288818 
Gardner, B., \& West, R. (2010). Public support in England for raising the price of cigarettes to fund tobacco control activities. Tobacco Control, 19(4), 331-333. https://doi.org/10.1136/tc.2009.033274

Gilbert, E. (2005). Contextualising the medical risks of cigarette smoking: Australian young women's perceptions of anti-smoking campaigns. Health, Risk \& Society, 7(3), 227-245. https://doi.org/10.1080/13698570500229655

Gilbert, E. (2008). The art of governing smoking: Discourse analysis of Australian anti-smoking campaigns. Social Theory \& Health, 6(2), 97-116. https://doi.org/10.1057/sth.2007.11

Gough, B., Fry, G., Grogan, S., \& Conner, M. (2009). Why do young adult smokers continue to smoke despite the health risks? a focus group study. Psychology \& Health, 24(2), 203-220. https://doi.org/10.1080/08870440701670570

Guest, G., Bunce, A., \& Johnson, L. (2006). How many interviews are enough?: An experiment with data saturation and variability. Field Methods, 18(1), 59-82. https://doi.org/10.1177/1525822X05279903

Guest, G., MacQueen, K. M., \& Namey, E. E. (2012). Applied thematic analysis. Los Angeles: Sage Publications. https://doi.org/10.4135/9781483384436

Haines-Saah, R. J., Bell, K., \& Dennis, S. (2015). A qualitative content analysis of cigarette health warning labels in Australia, Canada, the United Kingdom, and the United States. American Journal of Public Health, 105(2), e61-e69. https://doi.org/10.2105/AJPH.2014.302362

Hardcastle, S. J., Chan, D. C. K., Caudwell, K. M., Sultan, S., Cranwell, J., Chatzisarantis, N. L. D., \& Hagger, M. S. (2016). Larger and more prominent graphic health warnings on plain-packaged tobacco products and avoidant responses in current smokers: A qualitative study. International Journal of Behavioral Medicine, 23(1), 94-101. https://doi.org/10.1007/s12529-015-9487-x

Hastings, G., \& MacFadyen, L. (2002). The limitations of fear messages. Tobacco Control, 11(1), 73-75. https://doi.org/10.1136/tc.11.1.73

Heikkinen, H., Patja, K., \& Jallinoja, P. (2010). Smokers' accounts on the health risks of smoking: Why is smoking not dangerous for me? Social Science \& Medicine, 71(5), 877-883. https://doi.org/10.1016/j.socscimed.2010.05.036

International Tobacco Control Policy Evaluation Project. (2012). ITC Korea national report. Findings from the wave 1 to 3 surveys (2005-2010). Retrieved May 1, 2017, from http://www.itcproject.org/files/ITC_KoreaNR-ENG-Nov9--web-FINAL.pdf

Jarvis, M. J., \& Wardle J. (2006). Social patterning of individual health behaviours: The case of cigarette smoking. In M. G. Marmot \& R. G. Wilkinson (Eds.), Social determinants of health (2nd ed. pp. 224-237). New York, NY: Oxford University Press.

Jeong, J. H., Jeon, E. J., Lee, J. H., Han, J. Y., Kim, Y. S., Won, Y. S., \& Seo, M. A. (2010). A phenomenological study on smoking experience among female college students. Korean Journal of Health Education and Promotion, 27(3), 1-12.

Katainen, A. (2006). Challenging the imperative of health? smoking and justifications of risk-taking. Critical Public Health, 16(4), 295-305. https://doi.org/10.1080/09581590601089046

Katainen, A. (2010). Social class differences in the accounts of smoking - striving for distinction? Sociology of Health \& Illness, 32(7), 1087-1101. https://doi.org/10.1111/j.1467-9566.2010.01267.x

Kim, B. H., Cho, H. O., \& Lee, K. S. (2001). A qualitative research on adolescents' smoking motives and situational contexts. Journal of Public Relations Research, 5(2), 81-107.

Kim, M. S., \& Kim, A. K. (1997). The study of smoking behavior in college women: A grounded theory approach. Journal of Korean Academy of Nursing, 27(2), 315-328. https://doi.org/10.4040/jnas.1997.27.2.315

Kim, S. S., Son, H., \& Nam, K. A. (2005). The sociocultural context of Korean American men's smoking behavior. Western Journal of Nursing Research, 27(5), 604-623. https://doi.org/10.1177/0193945905276258

Kim, Y. M. (2016, October 17). Consumption rises after cigarette tax, clouding the debate. Korea Joongang Daily.

Korea Health Promotion Foundation. (2015). The national health promotion plan 2020. Retrieved February 22, 2017, from http://www.khealth.or.kr/b/98?\&di=\&bf=\&bi=9037\&page=0\&SRCH_TYPE=ALL\& SRCH_TEXT= 
Laurier, E., McKie, L., \& Goodwin, N. (2000). Daily and lifecourse contexts of smoking. Sociology of Health \& Illness, 22(3), 289-309. https://doi.org/10.1111/1467-9566.00205

Lee, S. M., Yoon, Y. D., Baek, J. H., Hyun, K. L., \& Kang, H. L. (2015). Assessing the effects of socio-economic impacts of major health risk factors and regulatory policies. Retrieved May 8, 2017, from http://www.nhis.or.kr/bbs7/boards/B0069/16002

Lupton, D. (1995). The imperative of health: Public health and the regulated body. London: Sage Publications.

Macnaughton, J., Carro-Ripalda, S., \& Russell, A. (2012). 'Risking enchantment': How are we to view the smoking person? Critical Public Health, 22(4), 455-469. https://doi.org/10.1080/09581596.2012.706260

Mair, M. (2011). Deconstructing behavioural classifications: Tobacco control, 'professional vision' and the tobacco user as a site of governmental intervention. Critical Public Health, 21(2), 129-140. https://doi.org/10.1080/09581596.2010.529423

Markus, H. R., \& Kitayama, S. (1991). Culture and the self: Implications for cognition, emotion, and motivation. Psychological Review, 98(2), 224-253. https://doi.org/10.1037/0033-295X.98.2.224

Mausner, B., \& Platt, E. S. (1971). Smoking: A behavioral analysis. New York, NY: Pergamon Press.

Mays, N., \& Pope, C. (1995). Rigour and qualitative research. British Medical Journal, 311(6997), 109-112. https://doi.org/10.1136/bmj.311.6997.109

McCool, J., Webb, L., Cameron, L. D., \& Hoek, J. (2012). Graphic warning labels on plain cigarette packs: Will they make a difference to adolescents? Social Science \& Medicine, 74(8), 1269-1273. https://doi.org/10.1016/j.socscimed.2011.12.043

McMaster, C., \& Lee, C. (1991). Cognitive dissonance in tobacco smokers. Addictive Behaviors, 16(5), 349-353. https://doi.org/10.1016/0306-4603(91)90028-G

Nichter, M. (2003). Smoking: What does culture have to do with it? Addiction, 98(Supplement 1), 139-145. https://doi.org/10.1046/j.1360-0443.98.s1.9.x

Organisation for Economic Cooperation and Development. (2017). Daily smokers (indicator). Retrieved February 14, 2017, from https://data.oecd.org/healthrisk/daily-smokers.htm

Petersen, A. R., \& Lupton, D. (1996). The new public health: Health and self in the age of risk. NSW, Australia: Allen \& Unwin.

Poland, B., Frohlich, K., Haines, R. J., Mykhalovskiy, E., Rock, M., \& Sparks, R. (2006). The social context of smoking: The next frontier in tobacco control? Tobacco Control, 15(1), 59-63. https://doi.org/10.1136/tc.2004.009886

Richards, L. (2005). Handling qualitative data: A practical guide (3rd ed.). Los Angeles, London, New Delhi, Singapore, and Washington DC: Sage.

Ross, H., Blecher, E., Yan, L., \& Hyland, A. (2011). Do cigarette prices motivate smokers to quit? new evidence from the ITC survey. Addiction, 106(3), 609-619. https://doi.org/10.1111/j.1360-0443.2010.03192.x

Scheffels, J., \& Schou, K. C. (2007). To be one who continues to smoke: Construction of legitimacy and meaning in young adults' accounts of smoking. Addiction Research \& Theory, 15(2), 161-176. https://doi.org/10.1080/16066350601179464

Schwekendiek, D.J. (2016). South Korea: A socioeconomic overview from the past to present. New Brunswick, New Jersey: Transaction Publishers.

Taylor, S. J., \& Bogdan, R. (1984). Introduction to qualitative research methods: The search for meanings (2nd ed.). New York, NY: Wiley.

The Cancer Council. (2017). 11.4 State and territory legislation. Retrieved February 16, 2017, from http://www.tobaccoinaustralia.org.au/chapter-11-advertising/11-4-state-and-territory-legislation

Vaismoradi, M., Turunen, H., \& Bondas, T. (2013). Content analysis and thematic analysis: Implications for conducting a qualitative descriptive study. Nursing \& Health Sciences, 15(3), 398-405. https://doi.org/10.1111/nhs. 12048

Wakefield, M., Coomber, K., Zacher, M., Durkin, S., Brennan, E., \& Scollo, M. (2015). Australian adult smokers' responses to plain packaging with larger graphic health warnings 1 year after implementation: Results from a national cross-sectional tracking survey. Tobacco Control, 24(Suppl 2), ii17-ii25. 
https://doi.org/10.1136/tobaccocontrol-2014-052050

Williams, S. J. (1995). Theorising class, health and lifestyles: Can Bourdieu help us? Sociology of Health and Illness, 17(5), 577-604. https://doi.org/10.1111/1467-9566.ep10932093

Wolburg, J. M. (2006). College students' responses to antismoking messages: Denial, defiance, and other boomerang effects. The Journal of Consumer Affairs, 40(2), 294-323. https://doi.org/10.1111/j.1745-6606.2006.00059.x

World Health Organisation. (2011). WHO report on the global tobacco epidemic, 2011: Warning about the dangers of tobacco. Retrieved May 8, 2017, from http://apps.who.int/iris/bitstream/10665/44616/1/9789240687813_eng.pdf

World Health Organisation. (2012). WHO global report: Mortality attributable to tobacco. Retrieved May 8, 2017, from http://apps.who.int/iris/bitstream/10665/44815/1/9789241564434_eng.pdf

World Health Organisation. (2015). WHO report on the global tobacco epidemic, 2015: Raising taxes on tobacco. Retrieved May 8, 2017, from http://apps.who.int/iris/bitstream/10665/178574/1/9789240694606_ eng.pdf?ua $=1 \& u a=1$

World Health Organisation. (2016). Tobacco. Retrieved February 2, 2017, from http://www.who.int/mediacentre/factsheets/fs339/en/

Yong, H., Borland, R., Hammond, D., Thrasher, J. F., Cummings, K. M., \& Fong, G. T. (2016). Smokers' reactions to the new larger health warning labels on plain cigarette packs in Australia: Findings from the ITC Australia project. Tobacco Control, 25(2), 181-187. https://doi.org/10.1136/tobaccocontrol-2014-051979

\section{Copyrights}

Copyright for this article is retained by the author(s), with first publication rights granted to the journal.

This is an open-access article distributed under the terms and conditions of the Creative Commons Attribution license (http://creativecommons.org/licenses/by/4.0/). 